\title{
DOIS GOLPES, DUAS DITADURAS
}

TWO COUPS, TWO DICTATORSHIPS

\author{
Eurelino Coelho* \\ eurecoelho@gmail.com
}

RESUMO: $\mathrm{O}$ artigo problematiza teses, ditas revisionistas, que ganharam peso na historiografia recente sobre o golpe e a ditadura militar brasileiras (1964-1985). A hipótese central é de que em tais teses se pode reconhecer as marcas de seu pertencimento a modos de ver o poder que se tornaram hegemônicos com a consolidação de formas contemporâneas de poder de classe.

PALAVRAS-CHAVE: Historiografia; Ditadura militar; Hegemonia

ABSTRACT: The article discusses some thesis, said revisionists that became domination recent historiography about the Brazilian military coup and dictatorship (1964-1985). The central hypothesis is that in such theses we can recognize the marks of their belonging to ways of seeing the power that became hegemonic with the consolidation of contemporary forms of class power.

KEYWORDS: Historiography; Military dictatorship; Hegemony.

\section{Introdução}

Já é quase uma tradição: a cada dez anos os historiadores sobem ao proscênio e tomam a palavra. Eles falam do golpe e da ditadura e, evidentemente, não contam a história todos do mesmo modo. Além disso, a cada década a narrativa de um mesmo autor pode adquirir novos matizes, em certos casos bastante surpreendentes. $O$ tema é polêmico, as interpretações frequentemente chocam-se umas contra as outras. É uma boa ocasião para revisitar questões sobre o ofício de historiador que, embora antigas, não perderam sua pertinência. Uma delas poderia ser formulada assim: o que está em disputa quando historiadores lutam entre si por diferentes visões do passado?

Uma resposta adequada a essa pergunta exige a consideração de múltiplos aspectos e foge do alcance deste exercício. No entanto, o exame de algumas das posições envolvidas no contencioso historiográfico sobre o golpe e a ditadura, que é a tarefa a que nos dedicamos para conceber este texto, pode fornecer elementos valiosos para pensar ao menos um desses aspectos: a relação entre o passado, que o historiador estuda, e o presente no qual

\footnotetext{
* Doutor em História. Professor do DCHF da Universidade Estadual de Feira de Santana (BA) - Graduação e Programa de Pós-Graduação - e pesquisador do LABELU (Laboratório de História e Memória da Esquerda e das Lutas Sociais).
} 
ele vive. Acontecimentos políticos de alta intensidade, como revoluções ou golpes de Estado, facilitam a observação dos modos pelos quais a percepção do pesquisador é modelada não somente a partir de sua fidelidade às fontes, mas também de seu pertencimento a certas maneiras de ver o mundo e, por conseguinte, a História. Não é o caso de secundarizar problemas técnicos e epistemológicos da produção do conhecimento que, com efeito, pesam significativamente no tipo de análise que tentamos aqui, mas de dar ênfase ao fato de que a subjetividade do historiador é um fator a ser ponderado quando fazemos a leitura de sua obra em perspectiva histórica. Claro que a subjetividade, neste sentido, é pensada não como

atributo da individualidade singular, mas como participação ativa de um sujeito numa determinada visão de mundo.

O argumento desdobrado a seguir parte de hipótese de que há um golpe historiográfico em curso, cujos movimentos tentarei descrever. São, afinal, dois golpes. $O$ de 1964, histórico, foi deflagrado quando Mourão Filho movimentou suas tropas em direção ao Rio de Janeiro, com as consequências que todos conhecemos. Este golpe pertence ao passado, produziu efeitos devastadores e de longa duração (nem todos, infelizmente, superados), mas foi finalmente derrotado junto com a ditadura nascida de seu ventre. 0 outro, historiográfico, está em andamento no presente e seu alvo imediato são certas memórias e maneiras de ver o passado que ele trata de proscrever e substituir. Manejando imagens do passado de modo a que apareçam com um peso que "oprime como um pesadelo o cérebro dos vivos", esses golpistas historiadores e cientistas sociais têm dado sua contribuição própria à sedimentação de modos de ver e de dar sentido a dilemas do presente. Tornaram-se eficazes funcionários de uma hegemonia cada vez mais espessa.

Refutar os argumentos empregados nesse golpe historiográfico é tarefa que já vem sendo bem realizada por historiadores que não abriram mão da perspectiva crítica. O que pretendo é apontar indícios de que, assim como o golpe de 1964 era muito mais que um ato de força dos militares, este outro é parte de um dispositivo de poder que envolve e ultrapassa a oficina dos historiadores e seus objetos fixados no passado.

\section{Histórias de ontem, lutas de hoje}

É prudente começar lembrando que, seja em sua formulação mais geral ou em ângulos mais fechados sobre temáticas específicas, as questões enunciadas acima tem sido bem estudadas. A tese de que "toda visão global da história constitui uma genealogia do presente", retomada aqui, foi defendida por Josep Fontana há mais de trinta anos. Fontana cuidou de distinguir seu argumento das abordagens "presentistas" à moda de Croce ou Collingwood, pois para ele o "projeto social em que o historiador inscreve a sua tarefa" é "algo que se realiza coletivamente e que tem uma função social." (FONTANA, 1998, p. 9). 
Estão disponíveis, por outro lado, excelentes análises historiográficas de corte temático orientadas por problemáticas mais ou menos afinadas com esta formulação, das quais o livro de Eric Hobsbawm (1996) sobre a historiografia da Revolução Francesa constitui um exemplo famoso, mas de modo algum isolado.

Também a historiografia dedicada ao golpe de 1964 e à ditadura começou a ser investigada por autores que dão importância às conexões entre a obra e o "projeto social" em que ela se inscreve. Um inventário mais completo das análises críticas da historiografia sobre o golpe e a ditadura certamente revelaria uma preocupação recorrente em várias delas com o fenômeno do revisionismo. O termo, sobre cuja precisão apresentarei reservas mais à frente, designa uma prática interpretativa promovida por estudiosos cujas pesquisas chegam a resultados mais ou menos coincidentes com as explicações e justificativas dadas para o golpe ou para a ditadura pelos seus próprios agentes e defensores. A despeito das coincidências entre seus pontos de vista e os de alguns ideólogos da ditadura, esses historiadores e cientistas sociais não fazem a defesa pública do golpe ou do regime militar. Demian Melo identifica três teses essenciais do revisionismo sobre o golpe e a ditadura: "esquerda e direita foram igualmente responsáveis; 2) na verdade, havia dois golpes em curso nos idos de 1964; 3) a resistência à ditadura não passou de um mito" (MELO, 2014b, p. 158).

A crítica a essa historiografia, via de regra, associa de alguma maneira o revisionismo detectado nos estudos do passado a tomadas de posição frente a questões políticas do presente. Caio Navarro de Toledo, que parece ter sido o primeiro a publicar uma crítica ao revisionismo, percebeu o fenômeno. Ele fez notar que uma historiografia que atribui à luta por reformas nos anos 60 a responsabilidade pela crise e também pelo golpe revela a

posição teórico-política desses autores [que concebem] assim, de forma
reticente e moderada, a luta por reformas substantivas na ordem capitalista.
Por conseguinte, fica distante do horizonte político e estratégico desses
acadêmicos a possibilidade de se construir uma democracia que - mediante
uma ampla participação política dos trabalhadores e dos setores populares
- enseje significativas conquistas sociais para as classes dominadas.
(TOLEDO, 2004, p. 46)

Marcelo Badaró Mattos, que já dedicou mais de um texto ao estudo do crescimento do revisionismo na produção historiográfica sobre o golpe (Cf. MATTOS, 2008), constata uma "guinada à direita" em parte dessa produção, já que ela passou a "somar-se ao coro dos que, desde 1964 querem absolver os golpistas para condenar os atingidos pelo golpe" (2005, p. 18). Ele alerta para que a interpretação dessa reviravoltanão a dissocie de "um processo maior de domínio conservador nas análises históricas e no pensamento universitário em geral, fruto em grande medida do neoliberalismo no contexto geral de avanço da ordem do 
capital" (Idem, p. 17). Em trabalho mais recente, Badaró Mattos retoma e aprofunda sua análise do revisionismo enfatizando o predomínio do paradigma culturalista e de seus pressupostos pós-modernos entre os historiadores (ele prioriza os que pesquisaram o golpe e a ditadura). Ainda uma vez o autor sublinha sua preocupação com os desdobramentos políticos das práticas historiográficas: "O culturalismo não é apenas uma moda acadêmica. Ele foi e continua sendo a base para muitas formulações políticas que interferem sobremaneira na nossa vida cotidiana." (MATTOS, 2014, p. 94). Até que ponto pode chegar essa interferência é o que ele sinaliza ao mencionar a repercussão de um texto, publicado em jornal de grande circulação,em que um famoso pesquisador da história da esquerda, exguerrilheiro com obras sobre o golpe e a ditadura, afirma serem politicamente equivalentes as figuras de Ernesto Che Guevara e de Osama Bin Laden.

Demian Bezerra de Melo foi quem mais avançou na análise da historiografia sobre o golpe, e manifesta preocupações semelhantes. Seu artigo de 2006, cujo título será parafraseado abaixo, é encerrado com uma menção aos evidentes nexos entre o revisionismo e as crises que, no final dos anos 80 , levaram vários historiadores à conclusão de que "as revoluções não são necessárias e, pior, conduzem invariavelmente ao Terror" e de que a ordem liberal capitalista seria "o melhor dos mundos possíveis". Os revisionistas comportamse como

verdadeiros intelectuais orgânicos da ordem neoliberal, já que sua revisão historiográfica é alimentada pela visão de mundo própria do consenso ideológico do fim da história. Não só é alimentada pois, ao rever o passado, esses intelectuais são também produtores dessa visão de mundo. (MELO, 2006, p. 128)

Na coletânea que organizou por ocasião do 50 aniversário do golpe, Demian Melo reconhece explicitamente a necessidade de "problematizar o uso público do conhecimento histórico entendido como parte da disputa por hegemonia." (2014b, p. 157) Seu artigo dá passos importantes nessa direção ao analisar a recepção calorosa das teses revisionistas por parte da grande imprensa, que tratou de dar-lhes ampla visibilidade.

Imprensa e hegemonia constituem o tema predileto de Carla Silva, que publica na mesma coletânea um estudo sobre a ação da imprensa na construção social da "ditabranda". Seu pressuposto é o de que há uma "convergência editorial entre editores e cientistas sociais comprometidos com o apagamento dos conflitos sociais da história brasileira". Sua pesquisa não é sobre a historiografia, mas é ela que vai mais longe na caracterização do fenômeno, que não ocorre apenas no Brasil, de uma

política de criação de consenso em torno da ditadura que busca, de diferentes formas, apagar sua existência, criar elementos no senso comum que estabeleçam aspectos positivos da ditadura, inclusive fazendo 
comparações com outras ditaduras para estabelecer as mais "brandas" e mais "duras".(SILVA, 2014, p. 195)

Carla Silva identifica, como sujeito dessa ação política, um "amplo espectro" que inclui não apenas militares, mas "inúmeros intelectuais orgânicos desse projeto social: donos de meios de comunicação e todo o seu aparato produtor de consenso; professores de institutos liberais; organizadores executores das práticas políticas e econômicas capitalistas."(SILVA, p. 195) Eu só teria a acrescentar que não há razão para excluir dessa lista os historiadores.

O golpe historiográfico encontrou, portanto, quem resistisse a ele. Na verdade, o principal resultado do esforço desses críticos nem foi destacado aqui: é o desmonte meticuloso e bem fundamentado, empírica e conceitualmente, das peças argumentativas erigidas pelos golpistas. Submetidos a minucioso escrutínio por profissionais competentes, os fundamentos das teses revisionistas vem sendo destruídos um após outro. Se, apesar de tudo, creio poder justificar minha intervenção nesse debate é porque proponho desenvolver um pouco mais extensamente algumas hipóteses contidas nos textos que acabei de citar que não puderam ser, até aqui, trabalhadas de modo mais detalhado pelos respectivos autores. Seguindo sugestões que encontro em seus textos, gostaria de pensar sobre o projeto social no qual se articula a historiografia golpista e sobre suas implicações políticas. Ou, para ser sintético: refletir sobre o significado que aquela prática historiográfica assume quando problematizada através do conceito de hegemonia. A questão é relevante, inclusive, porque é perfeitamente possível que o poder de convencimento das teses golpistas sobreviva à demonstração da debilidade de seus fundamentos.

Está, assim, longe de minha intenção propor ou defender aqui uma interpretação original sobre a história do golpe de 1964 e da ditadura que ele iniciou, embora minha posição a respeito da polêmica esteja, a essa altura, visível para o leitor. Para os objetivos modestos deste texto é suficiente lembrar que a ação armada de abril de 1964, que pôs fim ao regime constitucional em vigor, não foi um ato isolado cometido por generais autoritários. Ao contrário, ela foi a alternativa política desejada e longamente planejada por segmentos importantes da classe dominante brasileira com os quais as cúpulas militares mantinham, de longa data, intensas relações. Os argumentos empregados por René Armand Dreifuss (1981) para caracterizar aquele movimento como um golpe de classe não foram refutados, mesmo após 31 anos da publicação do seu livro admirável.

Ao golpe seguiu-se a ditadura que, do mesmo modo, não foi puramente militar. 0 regime autoritário, em todas as fases, foi reconhecido como seu pela classe dominante que, apesar do estreitamento dos canais de representação e negociação de interesses, nunca esteve realmente ausente dos espaços decisórios estratégicos. Aliás, é prudente não 
esquecer que formas de governo indireto da burguesia, de que as ditaduras militares são um exemplo entre outros, não são episódios incomuns na história das sociedades burguesas e nem restritos à periferia, como se pode verificar com os exemplos extremos de Alemanha e Itália no século XX ou dos bonapartismos na França do XIX.

Como estamos no meio de um combate, algum adversário poderia, a essa altura, questionar o caráter burguês da ditadura em razão da existência de uma oposição liberal que se manifestou ainda nos primeiros anos do regime. Sim, houve segmentos dissidentes entre os grupos sociais dominantes, mas como não haveria? Setores empresariais bem posicionados em espaços de poder nos anos de João Goulart tinham seus motivos para não apoiar o golpe e, por outro lado, a ditadura (como qualquer governo burguês) não tinha como assegurar o atendimento equânime aos interesses de todos os diferentes segmentos da classe. Na verdade a opção autoritária refletia justamente a radicalidade da crise política, isto é, a impossibilidade de compor e articular um consenso minimamente capaz de assegurar, simultaneamente, a unidade política entre os diferentes segmentos dominantes e a coerção legitimada dos grupos subalternos antagônicos. A ditadura durou enquanto garantiu solução para ambos os problemas: a alavancagem da acumulação de capital, apesar de suas contradições internas, criava as bases materiais (isto é: massas crescentes de maisvalor arrancadas dos trabalhadores cuja capacidade de resistência era quebrada pelo aparato repressivo) que tornaram possível algum consenso entre as principais frações da classe dominante, enquanto a agitação dos setores subalternos era reprimida pela violência estatal. Não por acaso foram a crise do "milagre", que corroeu as taxas de lucro, e a reemergência das lutas populares que levaram, a partir da segunda metade dos anos 70, à longa transição que pôs fim ao regime. ${ }^{2}$

Decerto, identificar o golpe como uma ação de classe e a ditadura como um governo burguês carrega consigo a exigência de estabelecer os agentes concretos desse poder e os modos como eles o exerceram: os programas que elaboraram e defenderam e os meios de fazê-lo, as práticas organizativas e articulatórias através das quais agiam, os avanços e derrotas obtidos nos diversos fronts para onde dirigiram suas iniciativas, o significado e o alcance de sua política nas diferentes conjunturas da luta de classes. Esta gigantesca tarefa não foi concluída, mas não é possível negligenciar a consistência empírica, além de teórica, e a alta relevância de resultados como os que foram alcançados por pesquisas como as de Sonia Regina de Mendonça (2010), mesmo que restritas às frações rurais da classe dominante brasileira, ou de René Dreifuss (1981; 1986; 1989). Seja em perspectivas semelhantes às de Mendonça e Dreifuss ou sob outros prismas conceituais, não é de agora que vários estudiosos ${ }^{3}$ confirmam o fato de que muitos dos mecanismos de poder da ditadura eram manejados diretamente por grupos burgueses civis. $O$ golpismo

\footnotetext{
${ }^{2}$ Cf. a argumentação desenvolvida por Fontes (2010).

${ }^{3}$ Só a título de ilustração, algumas obras que, em décadas diferentes, investigaram a atuação de setores civis (burgueses!) no golpe ou no contexto da ditadura: Pereira (1978), Starling (1986), Maciel (2004).
} 
historiográfico, por muito barulho que faça, não pôde apresentar nada que contestasse a sério as evidências produzidas por tais pesquisas quanto ao caráter de classe da ditadura ou do golpe de Estado que a iniciou. Eis que aparece, novamente, a questão a que aludimos acima. Teremos de examinar porque a má qualidade do argumento não enfraquece a posição dos golpistas.

Antes, porém, é preciso sanar uma lacuna nesta exposição. Até aqui tenho me referido ao golpe historiográfico sem o cuidado de melhor caracterizá-lo. É tempo de corrigir isso.

\section{Misérias historiográficas, astúcias sociológicas}

Golpes são atos de força, e isso vale também para os que são desferidos por historiadores. Faz muita diferença que a força, neste caso, seja mais simbólica que material, mas trata-se, mesmo assim, de um golpe. Quando falamos em força simbólica pensamos na posse de instrumentos que garantem o poder de produzir consensos de grande alcance, 0 poder de tornar algo extensamente visível ou invisível, de fixar e difundir amplamente certos significados e, ao mesmo tempo, desacreditar ou proscrever outros. Um poder assim é produzido mediante o emprego de diferentes recursos, principalmente de ordem material, possuídos por muito poucos, dentre eles a grande imprensa. No Brasil, sobretudo a partir dos anos 50, este mecanismo de poder é cada vez mais controlado por um grupo muito pequeno de empresas ligadas por diferentes fios a corporações internacionais. Laços econômicos e políticos de diversos tipos conectam esses grupos às frações mais poderosas e dinâmicas da burguesia no Brasil. Sua atuação tem importância singular no processamento dos interesses e das pautas daquelas frações e na conquista de adesão ou, no mínimo, consentimento por parte dos subalternos. Lidamos, aqui, com um setor estratégico na construção da hegemonia burguesa em nosso país, uma gigantesca e complexa máquina de fabricar consensos acerca de todos os temas considerados relevantes para o exercício do poder do capital. ${ }^{4}$

Nada de comparável está sob controle dos historiadores, quer individual quer coletivamente, nem mesmo dos mais famosos. O alcance da intervenção dos historiadores é estreito no Brasil, como se pode comprovar a partir de indicadores como as tiragens médias dos nossos livros ou a presença de público não especializado (que não sejam estudantes ou profissionais de História) nos nossos auditórios. Quase sempre é para nós mesmos que escrevemos e falamos. Bases estreitas de atuação e interlocução social e recursos materiais

${ }^{4} \mathrm{Cf}$. o estudo de Carla Silva (2009) que pôs a nu alguns laços de intimidade entre grandes veículos de imprensa e o grande capital. 
escassos resultam em um poder simbólico cujo peso político sempre foi modesto. É curioso notar que os campeões de vendas de livros sobre História no Brasil não são historiadores "de carteirinha", para desgosto de alguns. Se há, como penso, um golpe historiográfico em marcha, a força que o torna possível deve ser procurada não nos recursos à disposição dos historiadores, mas no que tornou a obra de certos historiadores valiosa para aqueles que controlam o poder real. E este é um fenômeno recente, cuja história não foi ainda estudada.

A pista a ser seguida tem a ver com a importância intrínseca do tema. O golpe de 64 e a subsequente ditadura possuem interesse imediato para aqueles a quem Florestan Fernandes designava "os de cima", pois põem em foco modos de ver e interpretar o próprio poder de Estado em sua manifestação mais direta. Isso não quer dizer, evidentemente, que a posição política dos dominantes sobre a ditadura permaneça imutável. Num primeiro momento, a defesa ruidosa do golpe e o apoio não menos entusiástico à ditadura, posições assumidas pela quase totalidade dos veículos da grande imprensa, eram expressões do fato, já mencionado, de que o regime foi assumido como seu pela classe dominante, ao menos enquanto demonstrou eficiência no cuidado dos seus interesses. Ora, os que se articularam para desfechar e apoiar o regime de força nunca deixaram de valorizar os serviços que lhes prestava a máquina fabricadora de consensos a que nos referimos. Deixemos de lado a hipótese de que a ditadura envolvia dispositivos de hegemonia, uma discussão que precisaria de espaço próprio para ser desenvolvida adequadamente. Consideremos, simplesmente, as evidências que confirmam o funcionamento, em níveis de rara intensidade, dos aparatos simbólicos ativados para justificar os atos, amealhar e consolidar apoio aos golpistas e ditadores, desde a grande imprensa até clubes de serviço e igrejas. ${ }^{5}$ As baionetas falaram mais alto no 1o de abril, mas não foi um monólogo: muitas outras vozes fizeram coro. Todavia, é o que queremos marcar, poucas daquelas vozes saíram das gargantas de historiadores ou de cientistas sociais.

Sabemos pouco sobre as razões pelas quais o consenso em torno do golpe e da ditadura aparentemente não envolveu setores numerosos ou representativos das faculdades de ciências humanas. Parece haver certo acordo entre os que estudaram as relações entre intelectuais e política nos anos de chumbo quanto à predominância, nos ambientes acadêmicos de então, de posições políticas à esquerda, por menos que se possa garantir um significado preciso para o termo. Num ensaio escrito entre 1969 e 1970 Roberto Schwarz (1978, p. 62) propôs a hipótese de uma hegemonia cultural da esquerda que sobreviveu ao golpe e que, aliás, iria muito além dos campi universitários: “Apesar da ditadura de direita há relativa hegemonia cultural da esquerda no país. Pode ser vista nas livrarias de São Paulo, cheias de marxismo, nas estreias teatrais (...) Em suma, nos santuários da cultura burguesa a esquerda dá o tom." Schwarz nuançava sua proposição com críticas às deformações nacionalistas do marxismo que vertebrava a cultura de esquerda no Brasil e com uma

\footnotetext{
${ }^{5} \mathrm{O}$ papel da grande imprensa na defesa do golpe e da ditadura tem sido estudado de modo sistemático e
} competente por Silva (2014). 
avaliação dos impasses com que se defrontaria essa hegemonia a partir de mudanças no cenário no final dos 60 .

Formulado nesses termos, o conceito de hegemonia perde muito de sua potência explicativa, pois o pressuposto de Schwarz é que a "esquerda" (ele não se refere a classes ou frações) detém a hegemonia no plano cultural, mas não nos demais espaços da vida social. Uma fratura tão profunda na totalidade social deveria causar estranhamento, mas o autor não parece se importar. Além do mais, Schwarz traça limites muito estreitos até mesmo para o "cultural", pois com este termo ele designa somente uma pequena parte da vida cultural do país, que diz respeito basicamente a pessoas que frequentam livrarias, vão a estréias de teatro, andam pelos "santuários da cultura burguesa". Toda a problemática da capilarização de uma visão de mundo para grandes massas humanas, que é o nervo da questão da hegemonia em Gramsci, fica fora da interpretação e, caso fosse considerada, não seria tão simples falar em hegemonia da esquerda.

A hipótese de Schwarz continua sugestiva, porém, desde que tomemos a palavra hegemonia em seu sentido rebaixado, como sinônimo de predominância ou tendência majoritária, e desde que saibamos que estamos nos referindo a um grupo social específico, pouco numeroso, intelectualizado e com meios de acesso a bens culturais sofisticados (em comparação com o conjunto da população). Tal hipótese, infelizmente, ainda espera por uma verificação empírica. Sem se preocupar com esta lacuna, há autores que partem da premissa de Schwarz para afirmar, também sem comprovação empírica, que, nas universidades, era o marxismo que predominava. Daniel Pécaut fala de uma tendência dos intelectuais brasileiros a

considerar o marxismo como o "horizonte inultrapassável" da época. Em fins dos anos 50, uma certa vulgata marxista difundia-se bem além dos setores localizados na esfera de influência do Partido Comunista: ela comanda a socialização política e cultural de grande parte daqueles que se identificam com as camadas intelectuais. (PÉCAUT, 1990, p. 16)

Milton Lahuerta, em trabalho sobre as interfaces entre a atuação política e profissional dos intelectuais do CEBRAP, é mais enfático:

Em realidade, tanto no CEBRAP quanto nos núcleos de humanidades das universidades, o marxismo, com seus mitos revolucionaristas [sic] e proletários, permaneceu, pelo menos até a primeira metade dos anos 80 , como a principal referência teórica. (LAHUERTA, 2001, p. 67).

A escassez de evidências (que, afinal, não parecem ter sido procuradas) não impede que aceitemos como razoável a suposição de que os espaços acadêmicos eram permeáveis à 
esquerda - pelo menos os militares e seus acólitos acreditavam seriamente nisso - e, por isso mesmo, pouco propensos a repercutir favoravelmente as iniciativas de apoio ao golpe de Estado ou ao regime militar. Seja por esta razão ou por outras, o que podemos constatar com alguma segurança é que o grosso da produção intelectual que tematizou o golpe ou a ditadura e que ganhou corpo a partir da década de 70, assumiu posições distantes da apologia e, não raro, abertamente críticas. No caso dos historiadores, bem verdade que os escritos sobre o golpe demoraram mais a aparecer, pois não é frequente que eles tomem o presente como sua matéria, mas o quadro é muito semelhante: é insignificante o número de trabalhos apologéticos do regime. Uma consulta a levantamentos bibliográficos como os que foram realizados por Ridenti (2001) ou por Fico (2004), este ainda mais extenso, confirma que as poucas publicações simpáticas ao golpe e ao regime foram quase todas externas às universidades brasileiras e, dentre essas, a grande maioria tinha os pés na caserna.

O que nos interessa sublinhar já está, a essa altura, visível para o leitor: o contraste entre esta postura dos acadêmicos e aquela dos grandes veículos de imprensa requer maior atenção. Aquele foi um momento em que, por mais que a classe dominante tenha participado ativamente dos eventos e se esforçado para amealhar apoio, cientistas sociais e historiadores permaneceram à parte. $O$ argumento de Pécaut exibe aqui uma de suas fraquezas, pois ele desenvolve sua questão em termos de adesão ou não daqueles intelectuais influenciados pela "vulgata marxista" a certo conceito de democracia que ele nem chega a problematizar. Por esta via conclui que, antes de 1964 "a posição que os intelectuais se conferem não os incita a manifestar um zelo excessivo quanto aos procedimentos democráticos" (PÉCAUT, 1990, p. 192). A hipérbole do "zelo excessivo" não esconde o anacronismo desta interpretação que, num tipo de tautologia negativa, mede excesso ou escassez de zelo democrático com base em uma concepção de democracia que, por vários motivos, não estava posta em questão pelos sujeitos envolvidos. Caminho muito mais promissor foi seguido por Fontes (1992), em texto que permanece lamentavelmente inédito, que se ocupou de qualificar as concepções de democracia formuladas por intelectuais brasileiros. De concreto o que sabemos é que quando os "procedimentos democráticos" foram golpeados em nome da democracia, os acadêmicos, marxistas ou não, recusaram seu apoio aos golpistas e não participaram do esforço de consenso mobilizado pelo aparato simbólico articulado pelos grupos sociais dominantes.

Entretanto, nem tudo é tão simples. O exame de uma pequena amostra dessa bibliografia que aparece a partir dos anos 70 permite que identifiquemos elementos que exigem mais esforço da análise. Aquilo mesmo que caracteriza o golpe historiográfico que ainda estava por vir, a saber, a enunciação de peças argumentativas que, sem assumir necessariamente uma posição abertamente apologética, corroboram, de algum modo, o discurso da ditadura sobre si mesma, começou a despontar muito cedo. Tomemos o caso de um sociólogo de fama internacional e publicamente identificado como de oposição à ditadura, Fernando Henrique Cardoso. Estamos em 1971, período mais duro da repressão, 
quando Cardoso publica um de seus mais conhecidos artigos, o Modelo Político Brasileiro. Sua perspectiva pretende afastar-se de "falácias metodológicas" como a "visão linear nas relações entre a economia e a política" que levam a que o Estado seja "concebido quase como 'comitê executivo' da burguesia" ou, inversamente, a que se tomem "os projetos políticos dos grupos no poder como condicionantes absolutos do processo social" (CARDOSO, 1993, p.85). Após compor sua conhecida caracterização do "modelo" como "dominação autocrática sob controle burocrático militar (...) assentado em bases economicamente dinâmicas" (CARDOSO, 1993, p. 106), Cardoso se propõe a pensar nas condições para a democratização. Há, segundo ele, dois fatores de desestabilização do "sistema" que atuam de fora sobre o regime, mas apenas negativamente, pois não são capazes de "gerar objetivos políticos e implementá-los". Esses dois elementos, que são a "repressão incontrolada e a ação armada da esquerda", cumprem um papel igualmente prejudicial, pois,

na medida em que impedem maior permissividade política, diminui a capacidade de o regime absorver grupos opositores e de gerar políticas capazes de passar pelo crivo da 'participação crítica' dos que a ele se opõem mas não querem perder influência política no Estado. (CARDOSO, 1993, p. 108)

E mais: as chances de evitar uma escalada de violência dependeriam da "capacidade que tenham os setores governamentais do regime ou as forças que se opõem a seus aspectos mais repressivos, (como a Igreja) para frear a corrida da violência política" (CARDOSO, 1993, p. 108). Em síntese: os extremos violentos, à direita e à esquerda, são impotentes para interferir nas políticas do regime, mas possuiriam o poder de "vetar" (o termo é de Cardoso) qualquer iniciativa que pudesse apontar saídas políticas em direção à democratização. Duas perguntas antes de prosseguirmos: qual o papel atribuído à esquerda nesse esquema? $O$ de entrave objetivo às possibilidades de avanço democrático. Alcançado este ponto, não estamos muito longe de imputar responsabilidades à esquerda, se não pelo golpe, ao menos pelo aprofundamento e permanência da ditadura. Notemos que esta tese só pode se manter porque o autor sequer menciona as organizações que não enveredaram pela luta armada (que sempre foram maioria) e porque, ainda mais grave, ele omite o fato de que a luta armada não era uma opção antes da ditadura, ou era somente para pouquíssimos militantes. Segunda pergunta: quais são os setores identificados como portadores de uma potência política real (positiva) e capazes de iniciativas com possibilidade de viabilizar avanços para a superação da ditadura? Aqui precisamos ler um pouco mais o "príncipe dos sociólogos".

Saltemos dez anos para outro artigo do mesmo autor, este dedicado expressamente ao problema da transição. Esquerda armada e linha dura dos militares eram coisas do passado em 1981, o Brasil assistia à ativação de grupos sociais subalternos cuja agenda 
combinava reivindicações de ordem material e política e cuja prática mudava a qualidade do espaço político. Apesar de tudo, Cardoso entende que a transição teria diante de si perigos novos. Ele procura respostas para a questão que, ele mesmo reconhece, nasce de uma perspectiva liberal: "quais as condições para democratizar a sociedade e institucionalizar democraticamente a vida pública?" (CARDOSO, 1993b, p. 263). Uma das primeiras seria livrar-se do equívoco de pensar que "sem a democratização substantiva na área social a democratização política é um engodo." (CARDOSO, 1993b,, p. 264) Aqui temos um dos afloramentos daquilo que muitos leitores de Cardoso, como Lahuerta (2001) consideram a valorização do político (não condicionar a avaliação das qualidades políticas do regime pelos conteúdos socioeconômicos expressos em suas formas), que desemboca, logo no parágrafo seguinte, na discussão da questão estratégica da "representatividade política". Apesar de registrar alguns limites da resposta liberal à questão, Cardoso despeja sua crítica contra a abordagem feita pelos "adeptos da teoria da crise de hegemonia", que cometem o erro da

recusa de pensar o Estado, que existe implícita na atitude 'basista' e na
valorização absoluta dos movimentos sociais frente aos partidos (...). Ora o
desprezo pelo Estado torna este tipo de pensamento generoso mas ao
mesmo tempo impotente para enfrentar o desafio do controle político das
sociedades complexas. (...) é teoricamente insatisfatório e politicamente
pouco eficaz imaginar uma política de transformação social que não diga o
que fazer no e com o Estado para redirecioná-lo em benefício da maioria.
(CARDOSO, 1993b, p. 264-5)

Ficamos sem explicações sobre a "atitude basista" que tanto incomodava o sociólogo, mas se formos minimamente rigorosos não devemos falar em desprezo pelo Estado ou pelos partidos por parte dos grupos subalternos que se mobilizavam naqueles anos. Eles traziam consigo uma disposição organizativa vigorosa, que resultou na criação de um partido político - o PT - e, pouco depois, na CUT. Tais iniciativas concretas de construção de formas de representação política, porém, não podiam ser aceitas por Cardoso, que considerava inaplicáveis ao Brasil modelos partidários que tinham sido funcionais apenas na Europa do século XIX: "Partidos de classe, no sentido estrito, pertencem à história de outras estruturas sociais." (IDEM, p. 272). Como a transição é caracterizada como um "processo de liberalização que visa ajustar a dominação burguesa, tal como ela pode se dar em países [como o Brasil]" (IDEM, p. 269), o equacionamento do problema da representação política deveria ter a função de criar as organizações que facilitassem a "longa guerra de posições" a que Cardoso se refere em outro artigo, através da qual "os trabalhadores, as classes médias assalariadas e os setores não-reacionários das classes dominantes poderão moldar no futuro um sistema mais aberto" (CARDOSO, 1993c, p. 232). É curioso notar que Cardoso expressamente se recusa a ver em tal "guerra de posições" qualquer hegemonia burguesa (CARDOSO, 1993d, passim). Voltaremos a esse ponto. 
Nossa segunda pergunta agora pode ser respondida. O "futuro mais aberto" terá as características de uma dominação burguesa ajustada e sua construção depende da atuação, principalmente no interior do Estado, de uma frente ampla da qual todas as classes participarão. Contudo, fica evidente que, para que seja viável uma política que conduza ao "futuro mais aberto", os trabalhadores não deveriam se fazer representar através de uma organização classista. Não se tratava de excluir a esquerda dessa política, mas de extirpar da esquerda tudo o que a vinculasse de modo demasiado estreito às classes subalternas. Impossível não lembrar que, 17 anos antes, algumas das alegações apresentadas para o golpe referiam-se aos aliados radicais de Goulart, os esquerdistas, que já não eram mais controlados pelo presidente e impunham sua agenda de reformas ao país. O que havia de intolerável na agenda dos radicais era, como sabemos, tudo o que ameaçasse posições de classe, como era o caso emblemático da reforma agrária.

Propus a releitura dos artigos de Cardoso para lembrar que certos aspectos dos argumentos que Melo (2006, 2014, 2014b) identifica nos autores que ele classifica como revisionistas já estavam presentes em intervenções bem anteriores, como aliás ele mesmo reconhece. A propósito, esta é a ressalva que faço ao termo revisionismo, pois neste caso não se pode falar de uma tradição interpretativa solidamente constituída que tenha sido submetida a uma reinterpretação radical. Antes, quando Fernando Henrique Cardoso escrevia, ou depois, no tempo em que Argelina Figueiredo (1993) concluiu e publicou a tese que Melo criticou de modo consistente, o que tínhamos era a proliferação de diferentes perspectivas de interpretação: Luiz Alberto Moniz Bandeira (1978) e René Dreifuss (1981) também eram lidos quase nos mesmos momentos. Os exemplos poderiam se multiplicar: as memórias apaziguadoras e quase arrependidas de Gabeira (1979) e Sirkis (1980) dividiram a prateleira das livrarias com os trabalhos muito diferentes de Gorender (1987) e Ridenti (1993). Não me parece possível identificar, em meio à uma tal dispersão polifônica, se havia e quais seriam as intervenções com peso hegemônico. Minha ressalva, porém, não deve ser entendida como a proposta de não empregar a palavra revisionismo, a menos enquanto não dispusermos de outra mais precisa. O que precisamos entender é como esta situação se modificou dramaticamente, a ponto de assistirmos hoje ao predomínio incontestável de certas interpretações enquanto outras são reduzidas a posições marginais ou à invisibilidade.

Lembremos que toda aquela polifonia assentava-se, no começo, sobre uma desconformidade entre o que os acadêmicos escreviam e o consenso que a classe dominante procurava construir em torno do seu regime. Sabemos que, a partir de meados dos anos 70, aquele consenso sofreu revezes crescentes até desaparecer. Vários grupos empresariais que haviam hipotecado seu apoio ao golpe e mesmo alguns que haviam participado diretamente no exercício do poder de Estado emitiam, agora, sinais de descontentamento, não raro 
acompanhados de reivindicações democráticas. ${ }^{6}$ Mesmo baluartes de primeira linha do consenso pró-regime, como a Folha de S. Paulo ou a revista Veja, mudavam suas linhas editoriais e, quando acharam oportunidade, trataram de desembarcar. ${ }^{7}$ A ditadura não respondia mais às necessidades das classes dominantes, mas a recomposição política em torno de outro projeto hegemônico foi difícil e demorada. Ao longo dos anos 80 as diversas frações da burguesia exibiram por mais de uma vez os sinais de sua fragmentação política embora, como bloco, continuassem capazes de defender a maioria de suas fortalezas dos riscos aportados pela luta de classes em fase histórica nova e desafiadora. Suas fraturas só não foram mais graves porque o enfrentamento de um antagonista comum assegurava-lhes um mínimo de unidade de (re)ação. É que, do outro lado da luta de classes, grupos subalternos gradativamente emergiam nos espaços públicos conduzindo experiências reivindicativas e organizativas autônomas e atacando com armas próprias, no discurso e na prática, os limites do Estado ditatorial. Entre eles ganhava corpo um projeto antagônico de contra-hegemonia que, em alguns momentos, assustou seriamente os "de cima". 8

A debilitação da capacidade hegemônica dos dominantes moldava um contexto ainda mais favorável à polifonia entre os acadêmicos. Entretanto, o fato de que o ambiente político era fortemente polarizado pela negação da ditadura pode ter contribuído para tornar menos visíveis ou para que fossem consideradas pouco significativas as diferenças existentes entre as abordagens, já que todas pareciam se alinhar na oposição ao regime. Abria-se um terreno propício para ambiguidades e mal-entendidos. Um caso que me parece emblemático é o da recepção das primeiras obras de Daniel Aarão Reis Filho. O tema que the conferiu notoriedade não foi propriamente o golpe ou a ditadura e sim a história de seus inimigos, as organizações de esquerda, em particular as de orientação marxista, e a história de revoluções socialistas no século XX. Ex-militante de uma daquelas organizações, Reis Filho fez uma avaliação muito dura da trajetória dos comunistas nos anos 60 , entendendo a derrota como consequência das próprias características constitutivas daquelas organizações. Os "mitos coesionadores" dos comunistas - "a revolução socialista, historicamente inevitável; a missão redentora do proletariado; a imprescindibilidade do partido de vanguarda, intérprete qualificado do devir histórico" e a "dinâmica excludente e antidemocrática das organizações comunistas" (REIS FILHO, 1990, p. 182) - estão entre as causas do fracasso. Os comunistas "preparam-se para a revolução afastando-se da sociedade que pretendem revolucionar, adquirem coesão interna em troca do afrouxamento dos laços com a sociedade" ((REIS FILHO, 1990, p. 19).

Não podemos nos deter aqui para mostrar como cada um dos pontos dessa crítica é elaborado de modo distorcido e sem maiores preocupações com a indicação de referências

\footnotetext{
${ }^{6} \mathrm{O}$ assunto foi bastante estudado, como se sabe. Um dos textos citados acima trata especificamente do "reencontro do empresariado com a democracia": Cardoso (1993d).

${ }^{7}$ Ver os dados apresentados por Carla Silva (2009).

${ }^{8}$ Tive oportunidade de desenvolver mais extensamente esta análise. Ver Coelho (2012).
} 
teóricas que sustentem as definições adotadas. De qualquer modo, o marco de chegada desse acerto de contas é a aspiração a uma renovação radical da própria esquerda marxista que, a ser feita nos termos propostos, levaria à completa descaracterização da esquerda como marxista. O autor assumiria de modo mais explícito essa sua aspiração no final dos anos 90. (REIS FILHO, 1997) Apesar dos ataques desferidos contra a esquerda revolucionária, do impacto nada desprezível da obra e de seu autor ser hoje considerado um dos ícones da historiografia dita revisionista, temos de lembrar que o livro, conquanto ensejasse algumas resenhas críticas $^{9}$, não foi recebido como um autêntico e poderoso golpe historiográfico (ou "revisionismo") nem por leituras feitas por ocasião do lançamento e nem mesmo pelos estudiosos contemporâneos do fenômeno. Demian Melo, já citado, dedica especial atenção a Reis Filho, mas apenas às obras posteriores ao aniversário de 40 anos do golpe. Não é um descuido. No ambiente polifônico em que o livro apareceu não havia motivo para dar maior importância às lamentações de mais um ex-guerrilheiro arrependido, mesmo que ele exibisse credenciais de historiador e que demonstrasse, desde cedo, habilidade incomum para galgar posições no campo intelectual. Tanto mais porque Reis Filho, enquanto pelejava contra seus moinhos de vento comunistas, continuou a intervir publicamente em defesa da memória dos perseguidos pelo regime (Cf. REIS FILHO, 1997). Mas este cenário estava para mudar profundamente.

As vacilações políticas da burguesia, expressões que eram da fragilidade na costura da hegemonia durante a transição, chegaram ao fim nos anos 90 . Com considerável atraso, os grupos sociais dominantes ajustaram suas posições na sustentação de um projeto político comum, nascido da necessidade de dar respostas à crise de longa duração que se aninhou nos centros da acumulação mundial de capital e, de lá, despejou seus efeitos por todo o globo. No Brasil, como em toda parte, a nova hegemonia burguesa traçou os marcos do realinhamento político das diversas frações da classe dominante e redefiniu a forma (não o conteúdo, evidentemente) da relação com os subalternos. Globalização, reestruturação produtiva e neoliberalismo foram nomes atribuídos a diferentes séries de iniciativas que, na busca desesperada (e raramente bom sucedida) para deter a corrosão crônica das taxas de lucro, incidiram sobre zonas estratégicas da luta de classes, aquelas mais próximas de impactar a extração de mais-valor. Ao mesmo tempo, essas iniciativas estabeleciam o quadro de referência para o trabalho de transformar em ideias dominantes as ideias que a classe dominante concebia a respeito das suas iniciativas e das necessidades que as geraram. Um trabalho que teria de ser confiado a especialistas, os intelectuais. ${ }^{10}$ Como se trata de fazer passar por universal a visão de mundo burguesa, a tarefa tem tanto mais chances de ser bem sucedida quanto menos deixar transparecer seu compromisso de classe.

\footnotetext{
${ }^{9}$ Não muitas, ao que parece. Se a revista Teoria \& Debate, vinculada ao PT, servir de indício de como foi a recepção do livro, ela publicou um comentário crítico (WEINER, 1990) seguido de outro favorável (VENCESLAU, 1991).

${ }^{10}$ Meu argumento sobre as mudanças recentemente ocorridas na luta de classes, que refaço aqui de modo bastante esquemático, está desenvolvido mais extensamente em Coelho (2012b).
} 
Acontece que nem sempre é possível apagar as digitais da cena do crime. Uma prioridade para o capital, neste novo cenário brasileiro, era o urgente apassivamento dos trabalhadores cuja movimentação autônoma representava risco máximo e, por isso mesmo, convertia-se em alvo primário. Parte desse objetivo foi perseguido com uso generalizado de meios coercitivos, quer procedentes do poder econômico direto ou do braço forte do Estado mas, embora indispensáveis, tais meios não seriam suficientes. Era imprescindível solapar tudo o que fosse associado à construção contra hegemônica que vinha do período anterior, particularmente a disposição dos subalternos para construir organizações autônomas, para mobilizar-se vigorosamente por demandas materiais e para apresentar-se nos espaços de luta com personalidade política e projeto próprios.

Mais explicitamente, a tarefa tinha, por um lado, objetivos negativos: destruir a legitimidade de uma das formas organizativas clássicas dos subalternos, a esquerda revolucionária, denunciando sua incompatibilidade genética com a liberdade e a democracia, sua natureza intrinsecamente golpista, autoritária; censurar a formulação de demandas fortes, "maximalistas", acusando-as pela inviabilização das regras do jogo democrático; reduzir ao anacronismo e ao ridículo projetos e discursos cuja referência central sejam a classe trabalhadora. Por outro lado, a cada negação correspondeu uma proposição: por uma esquerda nova, despida de veleidades radicais e conformada aos limites da ação política prescritos pelo próprio Estado burguês, aliás, "democrático"; por pautas e práticas reivindicativas centradas nos resultados e divorciadas de pretensões reformistas alargadas, que questionem o status quo; por projetos políticos formulados a partir de noções mais amplas, como cidadania e direitos, e concebidos de modo a acolher em sua diversidade a profusão de subjetividades que se apresentam no espaço político, sem reduzi-las a qualquer "identidade mestra"11 (ou seja, longe de qualquer unidade política com base na condição, vista como anacrônica, de classe).

A construção da nova hegemonia obteve resultados extraordinários, sendo um dos mais impressionantes a conquista da adesão entusiasmada de segmentos estratégicos da própria esquerda. ${ }^{12}$ Muitos aspectos estão implicados nessa operação, dentre os quais a vigência de uma concepção liberal, isto é, estritamente procedimental de democracia e a exclusão de concepções alternativas. Não podemos tratar aqui da maioria desses aspectos ${ }^{13}$ mas um deles não nos pode escapar - e com isso nos aproximamos novamente dos historiadores: a memória. Ela é um ponto sensível por duas razões. Em primeiro lugar porque é no terreno da memória que tem de ser travado o combate para controlar tanto os

\footnotetext{
${ }^{11}$ Cf. Hall (1997).

${ }^{12}$ A experiência de transformismo vivida pelos grupos dirigentes do PT me parece um caso emblemático. Cf. Coelho (2012).

${ }^{13}$ É extensa a bibliografia que, em perspectivas distintas, dedica-se à compreensão das novas formas da dominação burguesa no Brasil. As mencionadas a seguir são as que, além dos autores já citados, possuem relação importante (e diferentes níveis de acordo) com os argumentos deste artigo: Neves (2005; 2010); Martins (2009), Castelo (2013), Fontes (2010), Maciel (2012), Coelho (1998).
} 
significados atribuídos pelos "de baixo" às lutas do passado quanto as conexões que podem ser feitas com o presente. É uma batalha que envolve também sutilezas, pois ainda não foi possível anular o caráter positivo das imagens da luta contra a ditadura e pela democracia ou negar aos sobreviventes o direito à memória que muitos deles reivindicam. Além disso, aquelas imagens fornecem, ainda hoje, credenciais com valor político nada desprezível. 0 caminho passa a ser, então, o de desqualificar determinadas formas de lutar e seus protagonistas, exatamente aquelas esquerdas "que não eram de modo algum apaixonadas pela democracia, francamente desprezada em seus textos" (REIS FILHO, 2000, p. 70). Em segundo lugar, a nova hegemonia assumiu, no plano da política partidária, a forma de amplíssimas alianças que abrigam desde ex-guerrilheiros sofrendo de remorsos até defensores históricos da ditadura. Ao invés de evocar fantasmas de um passado incômodo, as forças hegemônicas impõem silêncio. E que os mortos enterrem seus mortos.

\section{Força: a virtudo do vício}

O esboço que acabo de fazer dos requerimentos da nova hegemonia permite retomar em plano mais organizado a questão que enunciei sobre o golpe historiográfico. Espero ser desculpado por haver realizado uma exposição demasiado esquemática e seletiva, remetendo questões de grande complexidade para indicações bibliográficas. A intenção era mesmo organizar o esboço de modo a dar evidência àquelas necessidades simbólicas do bloco dominante para cujo atendimento os historiadores eram - e são - os profissionais mais capacitados. A que resultados chegamos?

Assim como em 1964 e nos anos iniciais da ditadura, no período que se abriu na década de 90 os "de cima" não economizaram esforços para organizar o maior consenso possível em torno de suas necessidades, convertendo-as em necessidades gerais. No passado, porém, tiveram de se haver sem a ajuda de historiadores e cientistas sociais, enquanto, no segundo momento, esse serviço - o de responder aos requerimentos da hegemonia - Ihes é oferecido abundantemente por muitos de nossos colegas. Olhemos mais de perto.

Recuperemos, sob o prisma do que foi exposto a respeito da nova hegemonia burguesa, as teses que Demian Melo identifica como axiais da historiografia revisionista: a divisão da responsabilidade pelo golpe entre a direita e a esquerda, a afirmação do caráter golpista da esquerda e de seu descompromisso com a democracia. As conexões dessas teses sobre o passado com o projeto social hegemônico que inspira seus autores podem ser vistas com mais nitidez agora. Tanto os objetivos negativos (deslegitimar a esquerda revolucionária, conter em níveis não problemáticos as reivindicações dos subalternos e destruir a 
independência de classe) quanto os positivos (contribuir para a construção de uma nova esquerda, direcionar as pautas para resultados assimiláveis e elaborar um novo projeto político democrático-radical) da hegemonia burguesa contemporânea estão incorporados ao projeto social daqueles historiadores e cientistas sociais e transparecem em suas análises do passado.

Como reconhecem o próprio Melo e a maioria dos outros críticos dessa historiografia, essas postulações não são desenvolvidas exatamente do mesmo modo pelos diferentes autores, mas as diferenças não atingem o núcleo do argumento. Tudo nos leva a supor que o processo de assimilação dos requerimentos da hegemonia foi bastante desigual, começando muito cedo em casos como o de Fernando Henrique Cardoso, verdadeiro precursor na enunciação das condições políticas para "ajustar a dominação burguesa" em bases distintas da ditadura militar, tarefa que ele enfrentaria primeiro como sociólogo e depois, como príncipe. Outros casos, como o de Daniel Aarão Reis Filho, parecem avançar gradativamente e com muitas ambiguidades no início. Foi a consolidação da hegemonia burguesa, realizada ao longo da década de 90, que levou a uma mudança qualitativa e quantitativa nesse cenário. Aquelas formulações alinhadas com as necessidades simbólicas dos "de cima" foram catapultadas a posições proeminentes no campo historiográfico e nos espaços de discussão pública que se abriram para a temática. Melhor seria dizer: posições de força!

Exatamente porque o que produzem se tornou relevante para o bloco dominante, esses intelectuais passaram a gozar de um poder inalcançável por seus pares, poder que se expressa em fenômenos como tiragens gigantescas, inusitadas para livros de história, ou na grande exposição de suas obras e deles próprios em veículos da grande imprensa. Demian Melo (2014b) assinalou a ampla predominância dos revisionistas nas coberturas de imprensa, mais frequentes por ocasião de efemérides. O exemplo já mencionado, registrado por Badaró Matos, do artigo de Daniel Aarão Reis igualando Guevara a Bin Laden é só o mais escandaloso, mas de modo algum o único. No setor editorial, segundo Gilberto Calil (2014), a série de Elio Gaspari sobre a ditadura, quatro volumes pesados e caros, com duas mil páginas ao todo, vendeu mais de 400 mil exemplares entre 2002 e 2012. Os números já são maiores, pois Calil não tinha como contabilizar as vendas da nova edição, preparada para o aniversário de 50 anos do golpe e cuja tiragem inicial era de 30 mil volumes. Não dispomos de dados sobre tiragens ou vendas, certamente mais modestas, de autores como Marco Antonio Vila, Jorge Ferreira ou Daniel Aarão Reis Filho, mas qualquer pessoa habituada a frequentar livrarias (convencionais ou eletrônicas/virtuais) terá constatado o destaque visual dado a seus livros mais recentes ${ }^{14}$ - e poderá comparar com a observação de Roberto Schwarz, mencionada acima, sobre as livrarias de São Paulo nos anos 60 "cheias de marxismo". Outra dimensão estratégica do poder simbólico exercido pelos revisionistas seria descortinada se

\footnotetext{
14 Ou às edições recentes de seus livros antigos, como Aarão (2014), versão ligeiramente modificada de Aarão (2000).
} 
investigássemos os currículos e planos de ensino de História Contemporânea do Brasil nos cursos universitários de História. Meu palpite é que as interpretações inspiradas pela historiografia revisionista predominam amplamente.

Toda essa força simbólica é empregada para golpear alvos bem escolhidos. Discursos sobre o passado que não corroboram os significados despejados por essa parafernália hegemônica são desqualificados ou pior, reduzidos ao silêncio e ignorados. O golpe historiográfico volta-se contra os herdeiros acadêmicos de Dreifuss e Moniz Bandeira, mas não são eles os alvos prioritários. As armas estão calibradas para atingir um público muito mais vasto, o mesmo para o qual se dirigem as ações da nova hegemonia, da qual esta operação historiográfica é um mecanismo. O verdadeiro objetivo da guerra é a memória, os sentidos do passado tal como compartilhados por grandes massas humanas e as implicações que tal visão do passado projeta sobre o presente. As bibliotecas universitárias são apenas um dos muitos campos de batalha - outro, talvez mais importante, são os componentes curriculares cumpridos por novas gerações de professores de história e historiadores do futuro próximo.

A memória sobre os anos de chumbo não pode ser apagada, mas é depurada de tudo o que representa incômodo aos dominantes de hoje. Por isso, a propósito de tratar do passado, o golpe historiográfico atinge adversários do presente. Ao acusar a esquerda de responsabilidade pelo golpe militar ou pela continuidade agravada da ditadura, algo também acusatório está sendo dito sobre a esquerda anticapitalista de hoje, que já se encontra em situação bem difícil na correlação de forças, e sobre suas políticas avessas à conciliação de classes. Ao desenhar com cores lúgubres o caráter golpista dos que se mobilizaram pelas reformas de base, aparece no verso do papel, nas mesmas cores, a imagem dos projetos políticos que ainda insistem na possibilidade de que o poder político, em outras mãos e completamente reconfigurado, sirva para a promoção de mudanças substantivas e não para a perpetuação do status quo. Por fim, ao atacar o caráter supostamente antidemocrático dos que combateram a ditadura, assesta-se um golpe em todos os que ousam desafiar, por discursos e ações, os limites da concepção procedimental e se entregam à construção de formas políticas de democracia que não se apartem de seus conteúdos sociais, isto é, à edificação da democracia como poder popular, na direção apontada pela própria palavra $\delta \eta \mu о к р \alpha т і \alpha$.

REFERÊNCIAS BIBLIOGRÁFICAS

BANDEIRA, Moniz. O governo João Goulart. As lutas sociais no Brasil 1961-1964. Rio de Janeiro, Civilização Brasileira, 1978. 
CALIL, Gilberto Grassi. O revisionismo sobre a ditadura brasileira: a obra de Elio Gaspari. Segle XX. Revista catalana d'història, 7 (2014), 99-126.

CARDOSO, Fernando Henrique. O modelo político brasileiro. In: CARDOSO, Fernando Henrique. A construção da democracia. Estudos sobre política. São Paulo, Siciliano, 1993.

- Regime político e mudança social: a transição para a democracia. In: CARDOSO, Fernando Henrique. A construção da democracia. Estudos sobre política. São Paulo, Siciliano, 1993b.

Os impasses do regime autoritário: início da distensão. In: CARDOSO, Fernando Henrique. $A$ construção da democracia. Estudos sobre política. São Paulo, Siciliano, 1993c.

O papel dos empresários no processo de transição. In: CARDOSO, Fernando Henrique. $A$ construção da democracia. Estudos sobre política. São Paulo, Siciliano, 1993d.

CASTELO, Rodrigo. O social-liberalismo, Auge e crise da supremacia burguesa na era neoliberal. São Paulo, expressão Popular, 2013.

COELHO, Eurelino. A conversão democrática da esquerda no Brasil: aspectos teóricos. Cadernos do CEAS, 176, pp. 59-80,jul ago 1998.

COELHO, Eurelino. Uma esquerda para o capital. O transformismo dos grupos dirigentes do PT (1978-1998). São Paulo, Xamã - Feira de Santana, UEFS, 2012.

COELHO, Eurelino. Hipóteses sobre a luta de classes no capitalismo contemporâneo. In: COELHO, Eurelino e PENELU, Larissa (Orgs.) Lutas Sociais, Intelectuais e Poder. Feira de Santana, UEFS, 2012b.

DREIFUSS, René Armand. 1964: A Conquista do Estado. Ação Política, Poder e Golpe de Classe. Petrópolis, Vozes, 1981.

DREIFUSS, René Armand. A Internacional Capitalista. Estratégias e táticas do empresariado transnacional (19181986). Rio de Janeiro, Espaço e Tempo, 1986.

DREIFUSS, René Armand. O Jogo da Direita. 2a Ed., Petrópolis, Vozes, 1989.

FICO, Carlos. Além do Golpe. Versões e controvérsias sobre 1964 e a ditadura militar. Rio de Janeiro, record, 2004.

FIGUEIREDO, Argelina. Democracia ou reformas? Alternativas democráticas à crise política 1961-1964. São Paulo, Paz e Terra, 1993.

FONTANA, Josep. História: análise do passado e projeto social. Bauru, EDUSC, 1998.

FONTES, Virgínia. Démocratie et Révolution: Sciences Sociales et Pensée Politique au Brésil Contemporain (19731991). Thèse de Doctorat em Philosophie Politique. Paris X, Nanterre, 1992.

FONTES, Virgínia. O Brasil e o capital-imperialismo. Teoria e história. Rio de Janeiro, UFRJ, 2010.

GABEIRA, Fernando. O que é isso, companheiro? Rio de Janeiro, CODECRI, 1979.

GORENDER, Jacob. O combate nas trevas. São Paulo, Ática, 1987. 
HALL, Stuart. Identidades culturais na pós-modernidade. Tradução de Tomás Tadeu da Silva e Guaracira Lopes Louro. Rio de Janeiro, DP\&A, 1997.

HOBSBAWM, Eric. Ecos da Marselhesa. Dois séculos revêem a Revolução Francesa. S. Paulo, Companhia das Letras, 1996.

LAHUERTA, Milton. Intelectuais e resistência democrática: vida acadêmica, marxismo e política no Brasil. Cadernos AEL, v. 8, 14/15, pp. 53-93, 2001.

MACIEL, David. A argamassa da ordem. Da ditadura militar à Nova República (1974-1985). São Paulo, Xamã, 2004.

MACIEL, David. De Sarney a Collor: reformas políticas, democratização e crise (1985-1990). São Paulo, Alameda - Goiânia, FUNAPE, 2012.

MATTOS, Marcelo Badaró; Os trabalhadores e o golpe de 1964: um balanço da historiografia. História e Luta de Classes, vol.1, n. 1, pp. 7-19, abril 2005

MATTOS, Marcelo Badaró. O governo João Goulart: novos rumos da produção historiográfica. Revista Brasileira de História, vol.28, no.55, p.245-263, Jun 2008.

MATTOS, Marcelo Badaró. As bases teóricas do revisionismo: o culturalismo e a historiografia brasileira contemporânea. In: MELO, Demian (org.). A Miséria da Historiografia: uma crítica ao revisionismo contemporâneo. Rio de Janeiro, Consequência, 2014.

MARTINS, André Silva. A direita para o social. A educação da sociabilidade no Brasil contemporâneo. Juiz de Fora, UFJF, 2009.

MELO, Demian Bezerra de. A miséria da historiografia. Outubro, São Paulo, n. 14, pp. 111-130, 2006.

MELO, Demian Bezerra de. O golpe de 1964 e meio século de controvérsias: o estado atual da questão. In: MELO, Deminan Bezerra de (org.). A Miséria da Historiografia: uma crítica ao revisionismo contemporâneo. Rio de Janeiro, Consequência, 2014b.

MELO, Demian Bezerra de. Revisão e revisionismo na historiografia contemporânea. In: MELO, Deminan Bezerra de (org.). A Miséria da Historiografia: uma crítica ao revisionismo contemporâneo. Rio de Janeiro, Consequência, 2014.

MENDONÇA, Sonia Regina de. O Patronato Rural no Brasil recente (1964-1993). Rio de Janeiro, UFRJ, 2010.

NEVES, Lúcia Maria Wanderley (org.). A nova pedagogia da hegemonia. Estratégias do capital para educar o consenso. São Paulo, Xamã, 2005.

NEVES, Lúcia Maria Wanderley (org.). Direita para o social, esquerda para o capital. Intelectuais da nova pedagogia da hegemonia no Brasil. São Paulo, Xamã, 2010.

PÉCAUT, Daniel. Os intelectuais e a política no Brasil. São Paulo, Ática, 1990.

PEREIRA, Luiz Carlos Bresser. O colapso de uma aliança de classes. São Paulo, Brasiliense, 1978. 
REIS FILHO, Daniel Aarão. A revolução faltou ao encontro. Os comunistas no Brasil. 2ạ. Ed., São Paulo, Brasiliense, 1990.

REIS FILHO, Daniel Aarão. Um passado imprevisível: a construção da memória da esquerda nos anos 60. In: REIS FILHO, Daniel Aarão et. al. Versões e ficções: o sequestro da História. São Paulo, Perseu Abramo, 1997.

REIS FILHO, Daniel Aarão. Ditadura militar, esquerdas e sociedade. Rio de Janeiro, Jorge Zahar, 2000.

RIDENTI, Marcelo. O fantasma da revolução brasileira. São Paulo, UNESP, 1993.

RIDENTI, Marcelo. As esquerdas em armas contra a ditadura (1964-1974): uma bibliografia. Cadernos AEL, v. 8, n. 14-15, pp. 257-295.

SILVA, Carla Luciana. Imprensa e construção social da "Ditabranda". In: MELO, Deminan Bezerra de (org.). A Miséria da Historiografia: uma crítica ao revisionismo contemporâneo. Rio de Janeiro, Conseqência, 2014.

SILVA, Carla. VEJA: o indispensável partido neoliberal (1989-2002). Cascavel, EDUNIOSTE, 2009.

SCHWARZ, Roberto. Cultura e política, 1964-69. In: SCHWARZ, Roberto. O pai de família e outros estudos, Rio de Janeiro, Paz e Terra, 1978.

SIRKIS, Alfredo. Os Carbonários. Memória da guerrilha perdida. São Paulo, Global, 1980.

STARLING, Heloisa Maria Murgel. Os Senhores das Gerais. Os novos inconfidentes e o golpe de 1964. Petrópolis, Vozes, 1986.

TOLEDO, Caio Navarro de. 1964: Golpismo e democracia. As falácias do revisionismo. Crítica Marxista, Campinas, vol. 10, n. 19, pp.27-19, 2014.

VENCESLAU, Paulo de Tarso. Dedo na ferida. Teoria e Debate, 13, São Paulo, p. 77, mar 1991.

WEINER, Carlos. Trabalho de ideólogo. Teoria e Debate, 12, São Paulo, pp.69-70,out 1990. 